\title{
Study on large deformation characteristics and control technology of tunnel surrounding rock in debris flow accumulation area
}

\author{
Mu-shui Lin ${ }^{1, a}$, Cheng-ke Zhang ${ }^{1}$, Rong-jun $\mathrm{Wu}^{1}$, Fu-sheng Qiu ${ }^{1}$,Ning $\mathrm{Li}^{2}$, Li Chen ${ }^{2, b^{*}}$,Hao-sen Guo ${ }^{2}$ \\ ${ }^{1}$ Dacheng Engineering Construction Group Co.Ltd, Xiamen, Fujian ,361008, China \\ ${ }^{2}$ East China Jiaotong University, Nanchang, Jiangxi , 330013 , China
}

\begin{abstract}
Debris flow accumulation has the characteristics of loose and broken, low strength, poor stability and so on. When the tunnel passes through the debris flow accumulation area, it is easy to bring major safety hazards to the construction site. Based on the engineering background of Gangou tunnel crossing debris flow accumulation area in the fourth bid of Jiumian expressway, this paper establishes a numerical calculation model, studies the large deformation characteristics of tunnel surrounding rock in debris flow area, determines the reasonable reinforcement range of tunnel surrounding rock, and puts forward the comprehensive control technology of tunnel passing through debris flow accumulation body combining surface stability and underground reinforcement based on simulation results and field experience. The numerical results show that the deformation of surrounding rock and ground surface can be effectively controlled. The rationality of the proposed control measures is verified by field monitoring, which provides a reference for surrounding rock control of tunnel under type conditions.
\end{abstract}

\section{Introduction}

The geological conditions in the central and western regions of China are complex, and some weak surrounding rock areas with bad geological environment are often crossed in highway construction. In recent years, the disasters and accidents of tunnels passing through the bad geological environment have occurred constantly. Especially through the old debris flow area is more serious. Due to loose structure, poor mechanical properties, developed joints and fissures, the rock mass is relatively broken. the surface weathered rock mass is prone to collapse and collapse under the action of rainfall, earthquake and weathering erosion. it accumulates to the slope surface, the foot of the slope and even blocks the river course, providing a large amount of material sources for the debris flow, as shown in figure 1. Highways usually choose to stay away from or avoid bad geological areas such as debris flow when selecting lines, but with the rapid development of highways in China and the continuous improvement of line linear standards, more and more highway tunnels inevitably cross the debris flow accumulation area. Therefore, it is of great significance to study the large deformation characteristics of surrounding rock and the corresponding reinforcement control technology for the tunnel passing through debris flow accumulation body to ensure the long-term stability of the tunnel.

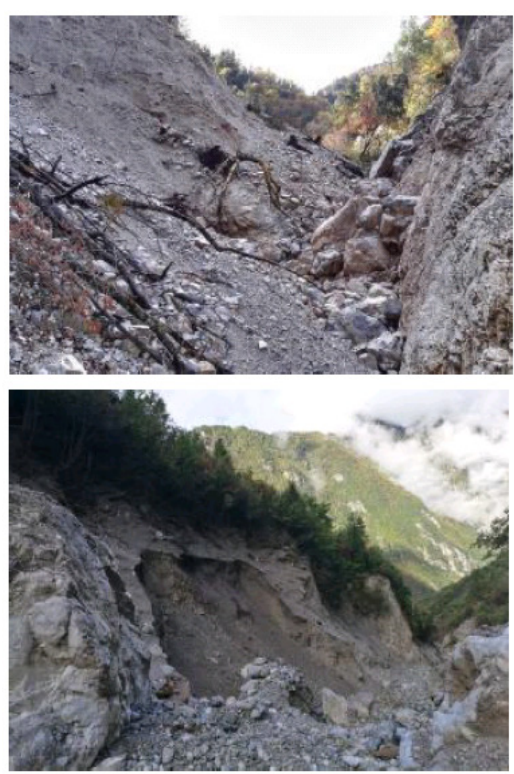

Figure 1. Topography of debris flow area

Scholars at home and abroad have done a lot of research work on the stability of debris flow accumulation body and reinforcement of debris flow accumulation body through tunnel, and have achieved many beneficial results. $\mathrm{Xu}$ Wei ${ }^{[1]}$ The construction technology of tunnel crossing shallow buried debris flow is summarized, the advantages and disadvantages of different construction schemes such

a7010240@qq.com

*Correspond author: bchenwen1995730@qq.com 
as open excavation method and hidden excavation method are analyzed, and the construction measures of foundation grouting reinforcement and foundation lining are explained. Li Tianbin and others ${ }^{[2]}$ Based on Futang tunnel project, a three-dimensional numerical model is established, and the main part of tunnel deformation is the settlement of dome. Xu Linrong and others ${ }^{[3]} \mathrm{A}$ simple, practical and operable damage grade evaluation mechanism is summarized. Wang Linfeng et $a^{\left[{ }^{[4]}\right.}$ The calculation method of tunnel structure through debris flow gully is explored, and the scour effect of debris flow must be considered in the calculation of debris flow gully tunnel structure, which provides a new idea for load analysis and internal force calculation of debris flow gully tunnel. Chen Hongkai ${ }^{[5]}$ The start-up, movement and erosion of debris flow are studied by numerical simulation software. Xin Bin et $\mathrm{al}^{[6]}$ The disaster reduction method of debris flow is put forward, the geological conditions and possible engineering difficulties of tunnel opening section are analyzed, and some defense engineering measures are given.

The debris flow accumulation body of Gangou tunnel in the fourth bid of Jiumian expressway has the characteristics of gully terrain, a large amount of loose solid accumulation, and even affected by earthquake. Debris flow disaster is very easy to occur, which brings huge safety risks to tunnel construction. Taking Gangou tunnel as the engineering background, this paper analyzes the characteristics of large deformation of tunnel surrounding rock in debris flow accumulation area by establishing three-dimensional numerical model. Combined with field experience, it puts forward technical measures for tunnel surrounding rock reinforcement through debris flow accumulation, and further verifies the rationality of comprehensive technical measures of surrounding rock reinforcement by establishing numerical model calculation and field monitoring.

\section{Engineering background}

The Gangou tunnel of Jiuzhaigou expressway is located in Jiuzhaigou County, Aba Prefecture, Sichuan Province. The main line starts from Qinglong village at the junction of Sichuan and Gansu, and ends in Wujiao Township, Jiuzhaigou County. The branch line starts from Shuanghe Township and ends at Zhongtian mountain village. According to the field survey, the tunnel site is mainly affected by debris flow. This paper takes Gangou tunnel crossing debris flow accumulation as an example. The proposed expressway is about $400 \mathrm{~m}$ away from the gully mouth, and Gangou tunnel passes through the debris flow gully from below. The landform of debris flow in K20 + $160 \sim \mathrm{K} 20+280$ section (Gangou) belongs to high mountain and gorge landform. The ridge is in the shape of edge angle, and the mountain body is mostly linear and convex slope. The slope gradient is relatively large, generally $30 \sim 38^{\circ}$ and the foot of the slope is generally $45 \sim 60^{\circ}$ due to the erosion of flood and debris flow. The shape of the gully is irregular, which is formed by two tributaries, and the plane is "Y". The satellite photo of the overall shape of the gully is shown in Figure 2. The material composition of debris flow accumulation is mainly gravel, and the lithology is mainly limestone and tuff. The area of debris flow area is about $9.36 \mathrm{~km}^{2}$, the total length of main gully is about $5.5 \mathrm{~km}$, the length of left branch gully is about $3.9 \mathrm{~km}$, the length of right gully is about $2.2 \mathrm{~km}$, and the average longitudinal gradient is $306 \%$.

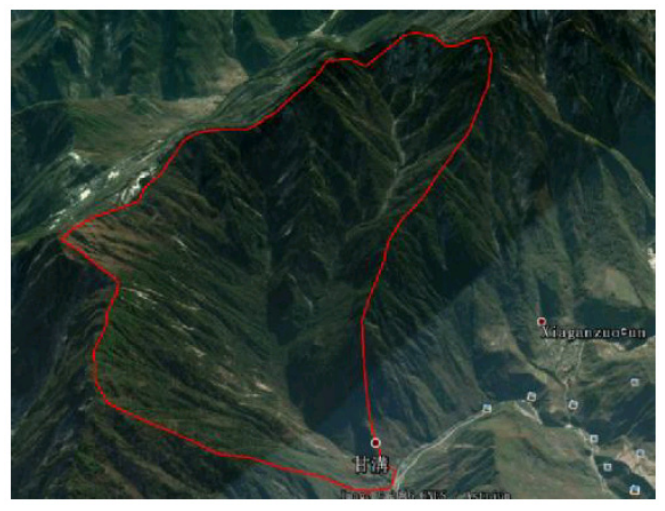

Figure 2.Satellite image of Gangou debris flow gully

\section{Large deformation characteristics of tunnel surrounding rock in debris flow accumulation area}

\subsection{Establishment of numerical models}

Because the accumulation of debris flow is relatively close it can be simplified as continuous medium. FLAC3D software based on continuum theory is used for numerical simulation. In order to study the large deformation characteristics of tunnel surrounding rock in debris flow accumulation area, the supporting effect is not considered at first, that is to study the large deformation characteristics of surrounding rock without support.

According to the section size of the tunnel, rhino software is used to model and then imported into FLAC3D software for simulation calculation. In order to eliminate the boundary effect, the model needs to have enough size. The boundary of the model should be 5 times of the width of the roadway. Therefore, the size of the model is $100 \times$ $50 \times 40 \mathrm{~m}$ (length $\times$ width $\times$ height). The boundary on both sides of the model adopts horizontal fixed boundary, the bottom is vertical fixed boundary, and the top is free boundary, as shown in Figure 3. Mohr Coulomb model is adopted for the constitutive model of tunnel surrounding rock, and the parameters of surrounding rock are shown in Table 1. 


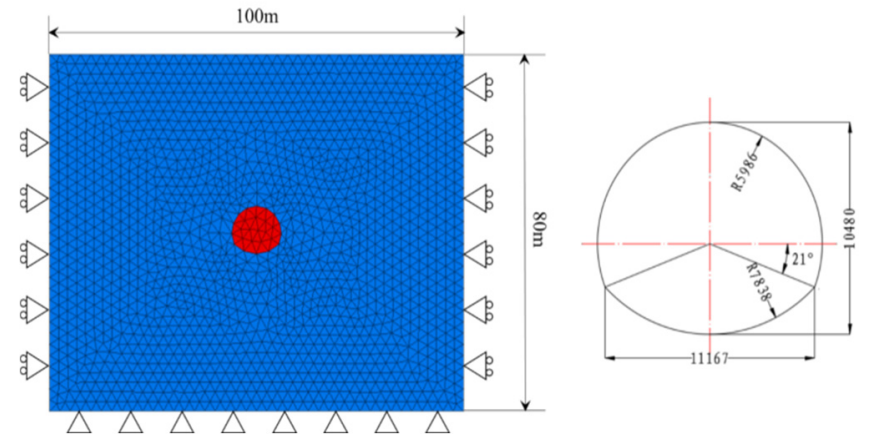

Figure 3. Numerical Simulation Model and Boundary Conditions

Table 1. Parameters of surrounding rock and supporting mechanics

\begin{tabular}{|c|c|c|c|c|c|}
\hline Type & $\begin{array}{c}\text { Bulk } /\left(\mathrm{kN} \cdot \mathrm{m}^{-}\right. \\
\left.{ }^{\prime}\right)\end{array}$ & $\begin{array}{c}\text { Elastic } \\
\text { modulus } \\
/(\mathrm{MPa})\end{array}$ & $\begin{array}{c}\text { Poisson } \\
\text { ratio } \\
(\mu)\end{array}$ & $\begin{array}{c}\text { Cohesio } \\
\mathrm{n} /(\mathrm{MPa})\end{array}$ & $\begin{array}{c}\text { internal } \\
\text { friction } \\
\text { angle } \\
/\left(^{\circ}\right)\end{array}$ \\
\hline $\begin{array}{c}\text { Debris } \\
\text { flow } \\
\text { accum } \\
\text { ulation }\end{array}$ & 1950 & 28 & 0.35 & 0.132 & 33 \\
\hline
\end{tabular}

\subsection{Analysis of numerical simulation results}

$$
\begin{array}{l|}
1.6640 \mathrm{E}+00 \\
1.5000 \mathrm{E}+00 \\
1.2500 \mathrm{E}+00 \\
1.0000 \mathrm{E}+00 \\
7.5000 \mathrm{E}-01 \\
5.0000 \mathrm{E}-01 \\
2.5000 \mathrm{E}-01 \\
0.0000 \mathrm{E}+00 \\
-2.5000 \mathrm{E}-01 \\
-5.0000 \mathrm{E}-01 \\
-7.5000 \mathrm{E}-01 \\
-1.0000 \mathrm{E}+00 \\
-1.2500 \mathrm{E}+00 \\
-1.5000 \mathrm{E}+00 \\
-1.5984 \mathrm{E}+00
\end{array}
$$

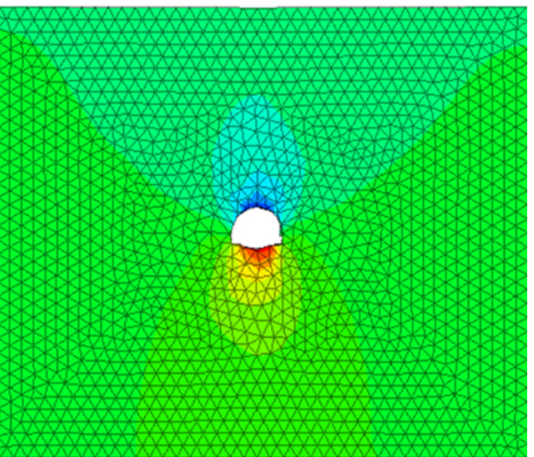

(a) Vertical displacement

$$
\begin{aligned}
& 1.3093 \mathrm{E}+00 \\
& 1.2000 \mathrm{E}+00 \\
& 1.0000 \mathrm{E}+00 \\
& 8.0000 \mathrm{E}-01 \\
& 6.0000 \mathrm{E}-01 \\
& 4.0000 \mathrm{E}-01 \\
& 2.0000 \mathrm{E}-01 \\
& 0.0000 \mathrm{E}+00 \\
& -2.0000 \mathrm{E}-01 \\
& -4.0000 \mathrm{E}-01 \\
& -6.0000 \mathrm{E}-01 \\
& -8.0000 \mathrm{E}-01 \\
& -1.0000 \mathrm{E}+00 \\
& -1.1451 \mathrm{E}+00
\end{aligned}
$$

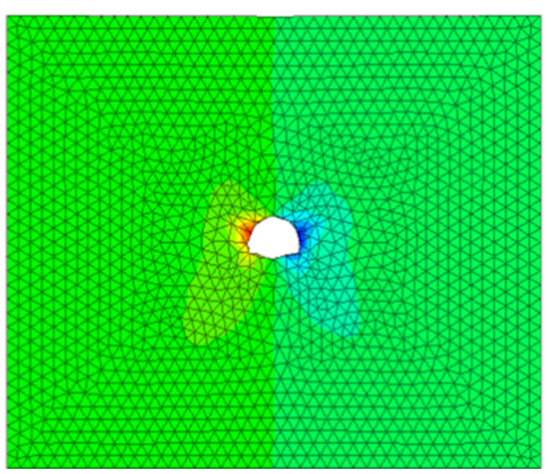

(b) Horizontal displacement

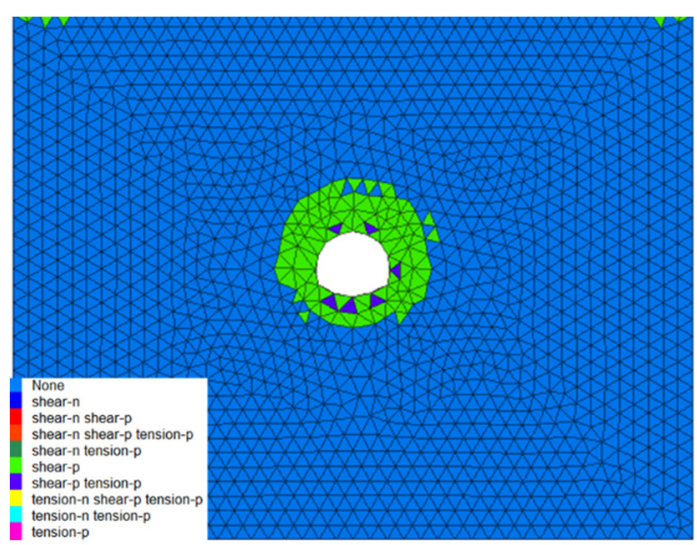

(c) Plastic zone

Figure 4. Numerical simulation results of tunnel surrounding rock without support

Figure 4 shows the vertical displacement, horizontal displacement and plastic distribution of surrounding rock without support. It can be seen from Figure 5 that after excavation without support, the maximum settlement of the tunnel top reaches $1.6 \mathrm{~m}$, and the maximum uplift at the bottom reaches $1.6 \mathrm{~m}$. The maximum deformation of left and right upper and shoulder is $1.3 \mathrm{~m}$ and $1.1 \mathrm{~m}$ respectively. The results show that the plastic zone around the tunnel is large, and the subsidence of the tunnel top leads to the development of the plastic zone at the top of the tunnel. The maximum plastic zone at the top is about $3 \mathrm{M}$, the maximum plastic zone on both sides is about $2 \mathrm{~m}$, and the maximum plastic zone at the bottom is about $1.5 \mathrm{~m}$. Therefore, the reinforcement range of tunnel surrounding rock in debris flow accumulation area should be at least 3 $\mathrm{m}$ beyond the outer contour line of tunnel excavation.

\section{Comprehensive Control Countermeasures of Tunnel Surrounding Rock Reinforcement in Debris Flow Accumulation Area}

In view of the engineering characteristics of debris flow accumulation as tunnel surrounding rock, such as poor stability, large porosity, belonging to soft rock to extremely soft rock and rich in water, the control countermeasures of combining ground stability with underground reinforcement are proposed. At the same time, the drainage channel is paved to dredge the surface water in time to ensure the stability of debris flow accumulation. Through the advanced pre grouting technology, the surrounding rock around the tunnel has good integrity and water resisting effect. The flow chart of comprehensive control measures for surrounding rock reinforcement of tunnel in debris flow accumulation area is shown in Figure 5. 


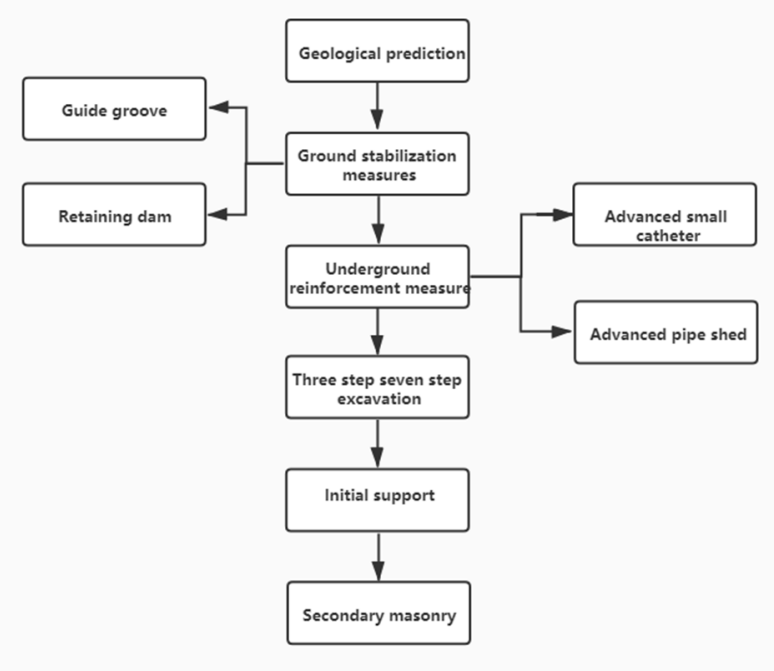

Figure 5. Flowchart of Integrated Control Countermeasures

\subsection{Surface control technology}

The concrete retaining dam is built in the ground debris flow ditch, the size is $50 \mathrm{~m}$ ( long) $\times 2 \mathrm{~m}$ ( high) and 0.5 $\mathrm{m}$ ( wide), and several drainage holes are set up. The drainage channel is arranged along the gully according to the shape, which requires the installation of waterproof board and concrete protective layer, and the distance from the tunnel contour line is not less than 5 times the tunnel diameter.

\subsection{Construction Technology of Grouting in Advance Large Pipe Shed}

(1)Concrete arch is used as the guide wall of long pipe shed outside C25 excavation contour line. Three I18 I-steel are embedded in the sleeve arch, the $\Phi 140 \mathrm{~mm}$ hole pipe is welded on the I-steel, the outside of the pipe is strengthened on the I-steel by $\Phi 14 \mathrm{~mm}$ steel bar cladding welding, and the welding length is more than $150 \mathrm{~mm}$. at each end Use horizontal hydraulic drilling rig to drill. After several connecting rods to complete the long pipe shed drilling. The deviation of steel pipe drilling is measured by inclinometer in drilling. It is found that the deviation exceeds the design requirement and should be corrected in time. Each hole is drilled into a steel pipe.

(2) To ensure sufficient strength, stiffness and toughness of the drill pipe joints, the drill pipe coupling sleeve shall be of the same material as the drill pipe, and the two ends shall be machined into an inner screw buckle (the end and end of the drill pipe outer screw buckle). The minimum wall thickness of the connecting sleeve shall $\geq 10 \mathrm{~mm}$. In order to prevent the drill pipe from quivering up and down under the dual action of thrust and vibration force, the straightening device should be set on the drill pipe and translated forward with the drill pipe drilling.

(3) Before drilling, the position of the borehole is drawn by the surveyor. When drilling, the arm of the drilling rig must be tightened on the face of the palm to prevent excessive vibration and improve the precision of drilling.
(4) Drilling rig hole drilling speed should be low, drilling depth of $20 \mathrm{~cm}$ into the normal drilling speed.

(5) When the first drill pipe is drilled into the tail of the rock layer for $20-30 \mathrm{~cm}$, the drill pipe is stopped, and the drill pipe is manually clamped with two pipe pliers (not to be clamped). The drill rig reverses at low speed and takes off the drill pipe. The drill rig returns to its original position along the guide rail, manually loads the second drill pipe, and installs the connecting sleeve at the front end of the drill pipe. The drill rig is sent to the tail of the first drill pipe at low speed, and the direction is aligned and connected into one body. Each long drill pipe can be carried out according to the above method.

6) When changing the drill pipe, pay attention to check whether the drill pipe is bent, damaged, the central water hole is smooth, etc.

(7) The diameter of the guide hole is $140 \mathrm{~mm}$, and the depth of the hole is $2 \mathrm{~m}$.

(8)After the drilling reaches the required depth, remove the drill pipe according to the same method and return the drill rig to its original position.

\subsection{Construction technology of leading small pipe grouting}

\subsubsection{Construction Method and Process}

Drill hole, small pipe along the hole into or with the wind drill into. For the surrounding rock of sand, the blowing pipe can be made $\varphi 20 \mathrm{~mm}$ small steel pipe, the blowing pipe can be inserted into the soil with high pressure air perforation, and the small pipe can be inserted after the hole is formed. The grouting adopts mortar pump or double hydraulic grouting machine, single liquid grouting is used in anhydrous section, and double liquid grouting is used in rich water section.

\subsubsection{Construction parameters}

The forerunner small pipe is made of seamless steel pipe with an outer diameter of $42 \mathrm{~mm}$ and a length of $450 \mathrm{~cm}$. The front end of the pipe is processed into a cone, and the reinforcement hoop is welded at the tail. The holes are staggered every $10-15 \mathrm{~cm}$ around the pipe wall, and the hole diameter is $8 \mathrm{~mm}$ (Plum blossom arrangement). The steel pipes are arranged along the excavation contour line of the tunnel, with an external angle of 5-70 and driven into the surrounding rock with a circumferential spacing of $0.5 \mathrm{~m}$, and the overlapping length of the two rows of small steel pipes in the longitudinal direction shall not be less than $1 \mathrm{~m}$. The pre grouting parameters of small pipe are as follows: grouting pressure $0.5 \sim 1.0 \mathrm{MPa}$, cement slurry water cement ratio $1: 1$, cement grade 425 .

\subsection{Primary and secondary lining construction technology}

(1)First spray. The wet spray method should be used to spray concrete on the rock surface immediately after the 
tunnel is excavated to prevent the relaxation of the rock body.

(2)Mortar anchor. Air drill hole, high pressure air blow hole, ox horn pump or grouting device grouting (or early strength Anchorage package), manual insertion of mortar anchor.

(3) Grouting anchor. In the construction of hollow anchor rod (should be good gasket, nut), should be installed first after grouting to ensure full grouting; construction of mortar anchor rod, medicine roll anchor rod, first put anchor agent (anchoring agent should be prehole immersion), and then install anchor rod.

(4)Hang the net. Outside the hole to make mesh, site splicing. The steel mesh is processed by mould, and the steel mesh is laid after the first layer of concrete is sprayed. The steel mesh should be laid with the fluctuation of the spray surface and carried out after the anchor rod is installed, and the gap with the spray surface should be controlled between $20 \sim 30 \mathrm{~mm}$.

(5)Construction of steel frame. The support of tunnel steel frame is divided into two types: steel frame and grille steel frame. The steel frame is mainly made of I-steel bending, and the grille steel frame is mainly made of four main bars and other steel bars. After the initial concrete spraying is completed in each part of the tunnel, the steel frame is installed in time, fixed with the positioning anchor rod, the radial anchor rod and the bilateral locking foot anchor pipe, the longitudinal $\Phi 22$ steel bar is connected, the steel frame is laid with the steel mesh, and then the concrete is sprayed to the design thickness.

\section{Numerical Model of Comprehensive Reinforcement of Tunnel Surrounding Rock in Debris Flow Accumulation Area}

\subsection{Model building}

Reference 3.1 The numerical model is established, in which the surrounding rock constitution of the tunnel is based on the Moore Coulomb model, the supporting structure is regarded as elastic material, the initial support, steel arch frame and shotcrete layer are simplified into a whole by shell unit simulation, the anchor rod and grouting bolt are simulated by cable unit, and the grouting of large pipe shed and small pipe is simulated by changing the mechanical parameters of rock mass in the grouting range. The mechanical parameters of the model supporting material are shown in Table $2^{[7]}$.

Table 2. Mechanical parameters of supporting materials

\begin{tabular}{|c|c|c|c|c|l|}
\hline Type & $\begin{array}{c}\mathrm{Bulk} \\
/ \mathrm{kN} \cdot \mathrm{m}^{-} \\
3\end{array}$ & $\begin{array}{c}\text { Elasti } \\
\mathrm{c} \\
\text { modul } \\
\mathrm{us} / \\
(\mathrm{MPa})\end{array}$ & $\begin{array}{c}\text { Poisso } \\
\mathrm{n} \mathrm{ratio} \\
(\mu)\end{array}$ & $\begin{array}{c}\text { Cohesi } \\
\text { on } \\
/(\mathrm{kPa})\end{array}$ & $\begin{array}{l}\text { intern } \\
\text { al } \\
\text { fricti } \\
\text { on } \\
\text { angle } \\
/\left(^{\circ}\right)\end{array}$ \\
\hline $\begin{array}{c}\text { Grouting } \\
\text { reinforcem } \\
\text { ent }\end{array}$ & 2100 & 550 & 0.32 & 54 & 36 \\
\hline
\end{tabular}

\begin{tabular}{|c|c|c|c|c|c|}
\hline $\begin{array}{c}\text { Shotcrete } \\
\text { support for } \\
\text { steel arch }\end{array}$ & 2950 & 27 & 0.3 & - & - \\
\hline $\begin{array}{c}\text { Anchor } \\
\text { bolt }\end{array}$ & - & $\begin{array}{c}21000 \\
0\end{array}$ & 0.23 & - & - \\
\hline
\end{tabular}

\subsection{Numerical simulation results and analysis}

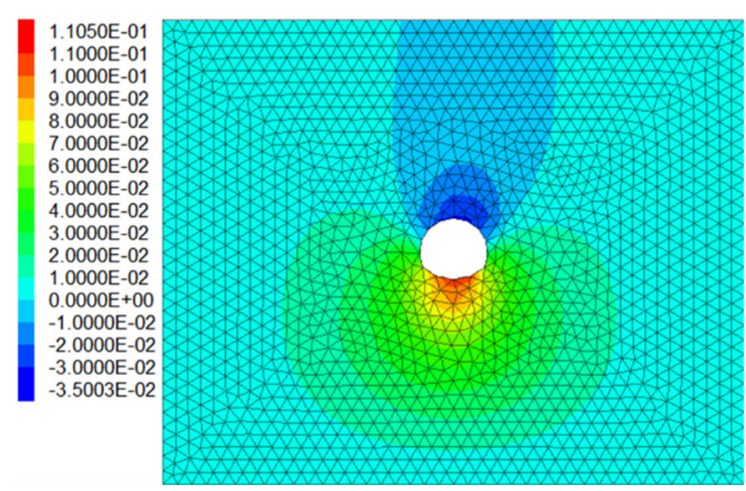

(a) Vertical displacement

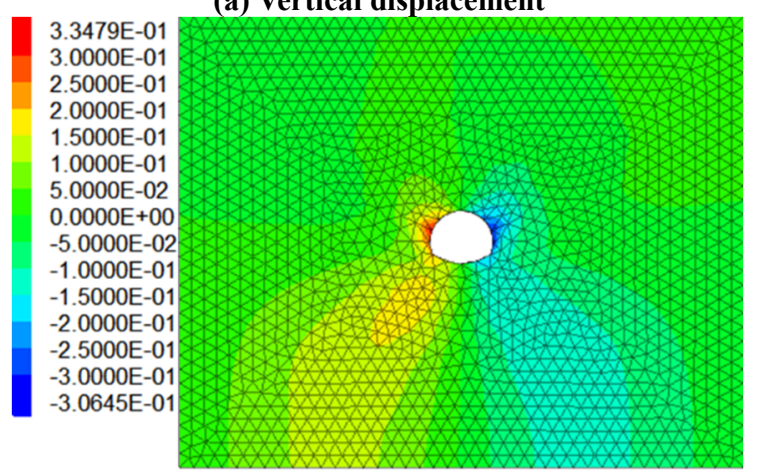

(b) Horizontal displacement

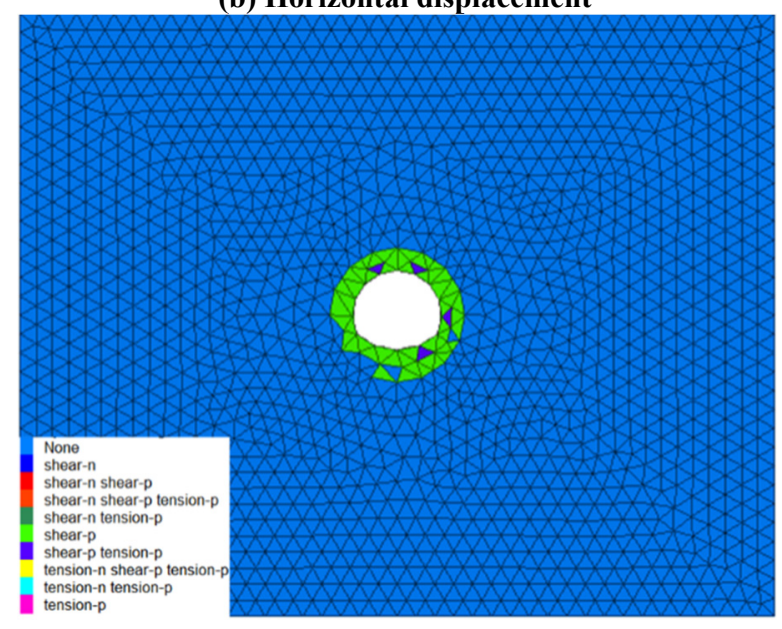

(c) Plastic zone

Figure 6. Numerical simulation results of surrounding rock reinforcement and support in tunnel

Figure 6 shows the vertical displacement, horizontal displacement and plastic distribution of surrounding rock under the condition of reinforced support. It can be seen from Figure 6 that the maximum subsidence of the top is $35 \mathrm{~mm}$ and the maximum uplift of the bottom is $110 \mathrm{~mm}$ after excavation under the reinforcement and support state. The results show that the maximum horizontal 
convergence of the left side is $33 \mathrm{~mm}$, and the maximum horizontal convergence of the right side is $30 \mathrm{~mm}$. The development depth of the plastic zone of the two sides and the floor is about $1.5 \mathrm{~m}$, which indicates that the comprehensive reinforcement measures of the tunnel through the debris flow accumulation have good control effect on the surrounding rock stability.

\section{Site rock deformation monitoring}

The monitoring points of tunnel section are arranged in the debris flow accumulation area of the tunnel to monitor the vault settlement and horizontal convergence of the tunnel. The layout of the monitoring points is shown in Figure 7.
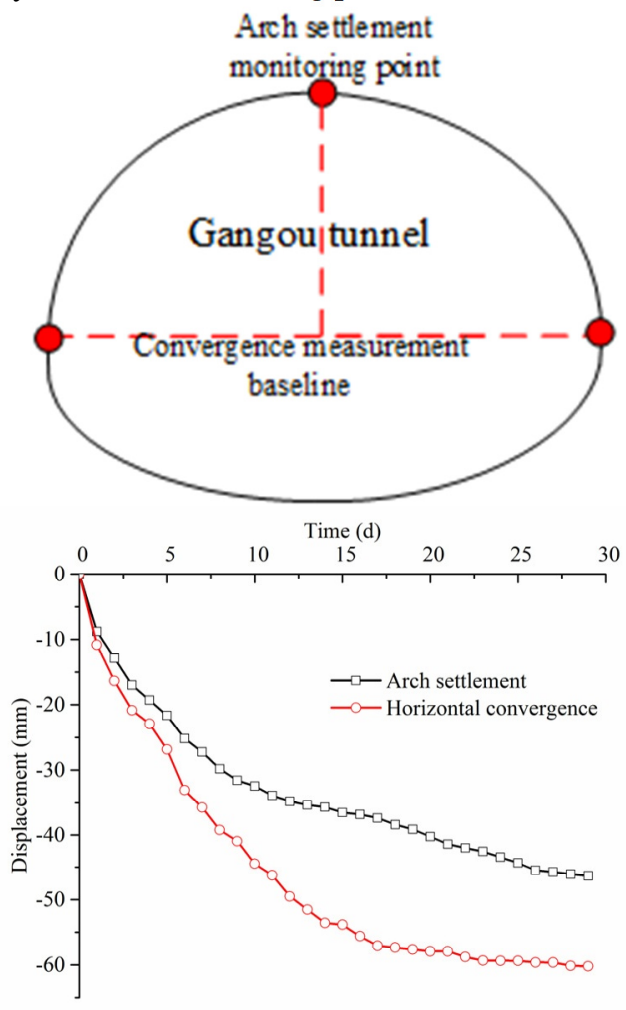

Figure 7. layout and monitoring curve of tunnel displacement measuring points

It can be seen from Figure 7 that the tunnel deformation monitoring was carried out for a period of 30 days. The monitoring results show that the deformation rate and deformation amount of the tunnel are large within $0 \sim 10$ days after excavation, and the deformation tends to be stable gradually between $10 \sim 30$ days. After 30 days, the maximum settlement of tunnel vault is about $46 \mathrm{~mm}$, and the maximum horizontal convergence is about $60 \mathrm{~mm}$, which are all within the allowable deformation range.

\section{Conclusions}

(1) Taking Gangou tunnel passing through debris flow area as the engineering background, a three-dimensional numerical calculation model of the interaction between the tunnel and debris flow accumulation is established. The results show that the main deformation of the tunnel is vault settlement, and the plastic zone of surrounding rock is about $3 \mathrm{~m}$ outside the excavation contour line when the tunnel passes through the debris flow deposit, so as to determine the reasonable reinforcement range of the tunnel surrounding rock.

(2)Combined with the previous engineering experience, the surrounding rock control measures combining ground stability measures and underground grouting reinforcement are proposed. The numerical results show that the settlement of the vault and the surface of the tunnel are effectively controlled, and the harmful deformation of the surrounding rock of the tunnel is controlled within the safe range.

(3)After 30 days, the maximum settlement of tunnel vault is about $46 \mathrm{~mm}$, and the maximum horizontal convergence is about $60 \mathrm{~mm}$. The comprehensive reinforcement measures of tunnel surrounding rock in debris flow accumulation area have played a good control effect .

\section{Acknowledgments:}

This work is supported by project(20202BABL214051) of Jiangxi Natural Science Foundation, science and technology projects (2018H0042 and 2016H0025) of Jiangxi Provincial Department of transportation.

\section{References}

1. Xu Wei. Construction Technology of Railway Tunnel Crossing Shallow Buried Mud-flow Slug [J].]; and Construction ,2015.42(12):71-72.

2. Li Tianbin, Liu Liang, Chen Guoqing. Numerical Simulation and Optimal Disposal of Debris Flow Accumulating Body in Tunnel Crossing J]. Journal of Engineering Geology ,2015,34(4):712-718.

3. Xu Linrong, Wang Lei, Su Zhiman. Evaluation of engineering vulnerability to debris flow disaster in tunnel engineering [J].]; and Geotechnical Mechanics 20(7):2153-2158.

4. Wang Linfeng, Tang Hongmei, Chen Hongkai. Settlement Principle of Debris Flow Tunnel Structure [J].] Journal of Chongqing Jiaotong University (Natural Science Edition)18(3):387-391.

5. Chen Hongkai, Chen Yeying, Tang Hongmei, et al. 2004: Deductive and Dynamic Study of Erosion and Erosion of Debris Flows and J]. Banks Highway ,12:149-154.

6. Xin Bin, $\mathrm{Su}$ Zhiman, $\mathrm{Xu}$ Linrong. Disaster Characteristics and Countermeasures of Debris Flow in Zhuofu Tunnel in Zhiliu County [J].] on Disaster Reduction Railway Construction 13(10):48-50.

7. Zhu Zhengguo, Zhu Yongquan, Wu Guangming, Wang Jian, Wang Daoyuan, Li Xinzhi. A study on the optimization of surrounding rock reinforcement and construction scheme of debris flow accumulation tunnel Journal of Railway Engineering 12(11):75$81+87$ 